\title{
Radio Observations during the Total Solar Eclipse of Aug. 31
}

$\mathrm{T}^{\mathrm{H}}$ $\mathrm{HE}$ radio observer of eclipse phenomena is subject to one important limitation which at once denies him the most spectacular successes and safeguards him from the most acute disappointments of the optical observer. He cannot make direct observations on the solar phenomena, but is restricted to a sort of indirect photometry of the ionosphere, a region already subject to such wide and ill-understood variations that no completely conclusive determinations are likely and no fully satisfactory control observations possible. At best, then, the agreement between the temporal sequence of radio phenomena and the sequence predicted from theories of the media will give strong support to one of the competing theories; at worst, a correlation of substantial magnitude will be submerged in random variations.

The eclipse of Aug. 31 was ill-situated, in place and time, for the mitigation of these difficulties. The line of optical totality did, indeed, fall happily for detailed observation, but totality was reached at a time of day when the diurnal curve of ionisation density in the ionosphere was already likely to be falling steeply, so that the temporary withdrawal of the ionising effect of ultra-violet light could only make the existing slope steeper, and the renewal of the effect could only be referred to a lower datum point. The centre line of the anticipated particle eclipse ${ }^{1}$ was likely, on any probable assumptions of particle velocity, to lie mainly over the ocean, and the only observing stations near the centre line (computed from the most probable velocity) were the necessarily under-manned and under-equipped Polar Year stations on the eastern coast of Greenland. These stations were still more heavily handicapped than were the American stations by the steeply falling diurnal curve, while western European stations were near the very sunset limit of eclipse, and consequently observed in the unstable and variable conditions which have, from the earliest days of radiotelegraphic observation, been known to characterise the sunset period.

The crucial problem to be examined was, of course, the discrimination between ultra-violet light and corpuscles as ionising agents for the two main regions of the ionosphere. There was substantial agreement that the Appleton region, above $200 \mathrm{~km}$., probably owed most of its ionisation to ultra-violet light, but while Chapman inclined to the view that the Kennelly-Heaviside region, at about $100 \mathrm{~km}$. height, was ionised by neutral solar corpuscles, Appleton and Naismith " accept ultraviolet radiation as one of the causes, if not the chief cause, of the ordinary diurnal replenishment of the ionisation in Region E" (the Kennelly-Heaviside region), and " regard the solar stream of neutral particles as causing the extraordinary effects on abnormal days". It may be remarked that further theoreticol development of this view would appear to be necessary to account for the remarkably limited single range of height within which these mixed agencies develop maximal ionisation density.
Further work must also take account of the redistribution in the horizontal of that ionisation which results from the injection of ionising agents into regions outside the vertical column of ionosphere directly sampled by the modern technique of short. base echo sounding. The replenishment of ionisation in the Kennelly-Heaviside region after sunset, noticed by Appleton and Naismith ${ }^{2}$ in England, by Schafer and Goodall ${ }^{3}$ in the United States, and by Ranzi ${ }^{4}$ in Italy, may possibly be referred to this horizontal redistribution.

The radio observations made in connexion with the total solar eclipse of Aug. 31 were of three kinds. The first and most directly interpretable class contained short-base echo experiments designed to give direct evidence of the state of ionisation vertically above the experimental stations. These stations were, in some cases, existing research establishments, but the Canadian authorities set up special stations at points vertically under the lines of optical totality for the two principal regions (these lines lying somewhat south-west from the line of totality at ground level), and Canadian and United States expeditions also proceeded to points as far eastward as were conveniently attainable on the American continent, in order to sample the particle eclipse. The second class of observation was made on long distance signals specially emitted for the purpose on frequencies and trajectories chosen to enhance the relative importance of one or other of the ionised regions in its normal and ' eclipsed' states. The collaborations amongst the American Telephone and Telegraph Company in the United States and the Post Office and Department of Scientific and Industrial Research in Great Britain, and between the British and Canadian Marconi Companies, belong to this category. The third class of observation dealt with the quality of reception of signals normally available, and included the considerable body of amateur collaboration in two continents, the results of which will doubtless become available at an early date.

It need scarcely be said that detailed observational results and considered conclusions are not yet available for discussion. But by the courtesy of the many authorities concerned the preliminary data, specially communicated for publication in Nature, may be summarised here. The data will be taken in geographical order, from the eastern fringe of the particle eclipse to the western fringe of the optical eclipse.

Dr. Van der Pol, observing at Eindhoven, was so situated that the particle eclipse (here regarded as an eclipse of $1600 \mathrm{~km} . / \mathrm{min}$. particles) was partial only, and was overtaken halfway through by the incidence of ground sunset. It was, then, not surprising that in such unfavourable geographical conditions no marked anomaly in Kennelly-Heaviside layer conditions was observed during the eclipse.

The two stations of the Department of Scientific and Industrial Research, namely, the Polar Year station established, in co-operation with the British

No. 3280, VoL. 130] 
National Polar Year Committee and the Norwegian Committee for Cosmic Physics, at Tromsö, and the Radio Research Station, Slough, were, despite their geographical separation of 1330 miles, similarly situated in respect of the particle eclipse, which ended about the time of local sunset at both stations. Prof. Appleton's station at King's College, London, and Mr. J. A. Ratcliffe's station at the Cavendish Laboratory, Cambridge, both working, as always, in close co-operation with Radio Research Station, formed with Slough a group of stations thus unfavourably situated in south-east England, each of which undertook a distinct section of a single observational programme of short-base echo work. The Post Office stations at Dollis Hill, Baldock, and Cupar, and the Slough station, participated similarly in a single programme of organised observation on trans-Atlantic radio channels.

The Tromsö observations were complicated by the fact that the ionosphere was in the process of

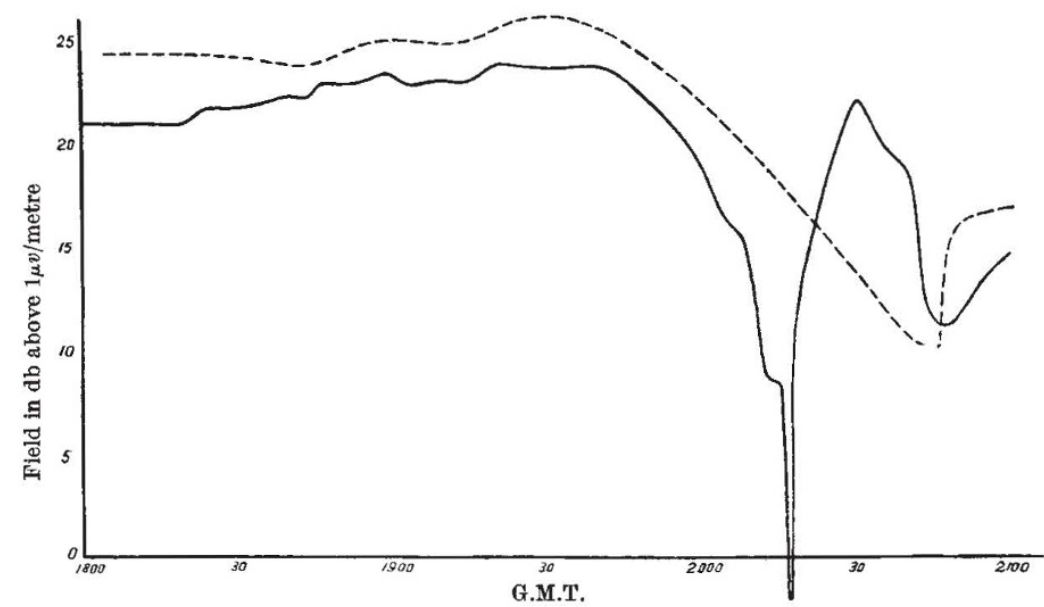

FIG. 1.-Field strength measurements taken at Cupar Radio Station on $60 \mathrm{kc} . / \mathrm{sec}$. of Rocky Point, U.S.A., transmissions. - - - - Aug. 30;

tron density in this layer fell to a selected critical value, low enough to permit the escape of 70 metre waves, nearly an hour earlier on the eclipse date than on each of the adjacent control days. This time of critical value was confirmed by London. A slight rise in the effective height of the Appleton layer was observed at Cambridge at 1830 on Aug. 31. There are here two very slender suggestions that the cutting off of the corpuscular ionising agent permitted recombination to bring about an exceptionally early night condition, and increased the height to which it was necessary to proceed before finding a particular ionisation density.

Slough concentrated attention especially on the Kennelly-Heaviside region, about which Cambridge and London were able to supply confirming evidence. It is firmly established by the combined data that the ionisation density in this layer was notably lower in the late afternoon of Aug. 31 than on Aug. 30 or Sept. 1; the equivalent electron density being about $2 \times 10^{5}$ electrons per c.c. on both control days. At 1815 on Aug. 31 the value of $2.5 \times 10^{5}$ was momentarily attained, but in general the value lay below $2.0 \times 10^{5}$. At 1851 the density was below $0.6 \times 10^{5}$, at 1905 this value was exceeded, and from 1940 to 2030 the average density was of the order of $1 \times 10^{5}$. There is, then, definite evidence of a relatively low ionisation density at the time of the partiele eclipse, followed by a notable rise. This low density at 1830 has no counterpart on the control days, but the rise between that hour and 1900 is paralleled by the events of Aug. 30.

The British observations on trans-Atlantic signals were made

recovery from a severe magnetic disturbance. Had the station been farther from the sunset fringe, this magnetic disturbance might have been of importance in the study of the particle eclipse, but the general result of the superposed conditions was that, on a preliminary survey at least, the Tromsö record gives no suggestion of eclipse effects.

The results from Cambridge, London, and Slough may conveniently be considered together. Cambridge and London, concentrating special attention on the Appleton layer, agreed in showing that the ionisation density in this layer increased between 1800 and 1900 G.M.T., suggesting that any effect of the particle eclipse on this layer was (1) over before 1815, (2) absent, or (3) overlaid by another cause of increased ionisation density. A notable decrease of ionisation observed by London about 1700-1720 might have supported (1), suggesting the eclipse of unexpectedly slow particles of low penetrating power, but the occurrence of a similar effect of less magnitude, on the succeeding control evening, was against this interpretation. On the other hand, Cambridge found that the elec- on frequencies of $13,390 \mathrm{kc} / \mathrm{sec}$. (wave-length $22.4 \mathrm{~m}$.), $8665 \mathrm{kc}$. $/ \mathrm{sec}$. $(34.7 \mathrm{~m}$.), and $60 \mathrm{kc}$. $/ \mathrm{sec}$. $(5000 \mathrm{~m}$.) emitted from the stations of the American Telephone and Telegraph Co. at Laurenceville, of the General Electric Company at Schenectady, and of the American Telephone and Telegraph Co. at Rocky Point respectively. The 13,390 kc./sec. channel was watched at Baldock and Cupar, and the ray angles and state of polarisation were measured at Slough; the $8665 \mathrm{kc}$./sec. channel was watched at Slough; while the $60 \mathrm{kc}$./sec. channel was watched at Dollis Hill, Baldock, and Cupar.

It may be said at once that on the higher frequencies, no phenomena were observed which lay outside the normal range for the average afternoon; the impossibility of isolating any eclipse event on these channels is emphasised by a very great contrast in behaviour from one control day to another. A complete fade-out between 1951 and 2000 G.M.T. on Aug. 31 was observed on the $13,390 \mathrm{kc}$./ $/ \mathrm{sec}$. channel, but, as just indicated, no special signifi. cance can be attached to it.

The $60 \mathrm{kc}$./sec. channel, however, is subject to a

No. 3280, VoL. 130] 
very much smaller range of normal variation, and the fact that this frequency range must involve the Kennelly-Heaviside region as an important element in propagation gave it an especially important place in the programme. Dollis Hill and Baldock did not observe any important anomalies on the eclipse date or on the control days. Cupar, on the other hand, experienced a complete fade-out between 2015 and 2018 G.M.T. on Aug. 31, followed by a recovery to a relatively high signal level at 2030 . This sequence of phenomena was the only departure from a very close similarity between the variation curves for Aug. 30 and 31, as shown in Fig. 1. A complete fade-out of this type is such a rare event on the $60 \mathrm{kc} . / \mathrm{sec}$. channel that it is certainly significant, and the time of its occurrence, although somewhat surprisingly early, is so close to the time of minimum illumination of the lower ionosphere over the early part of the trajectory, that it may be concluded with some confidence that we have definite evidence of an ultra-violet eclipse effect on the Kennelly-Heaviside layer.

Details of the observations made by the Dutch and French Polar Year parties at Angmagssalik and Scoresby Sound respectively are, unfortunately, not yet available.

The Canadian joint observations are summarised in a special communication kindly cabled by Prof. A. S. Eve. The special expeditions sent to Vanleek Hill, Ontario, and to Kingston, Ontario, under the direction of Dr. J. T. Henderson and Dr. D. C. Rose respectively, report distinct losses in the ionisation of both the Kennelly-Heaviside and Appleton layers during the period of optical eclipse. The special expedition to Corner Brook, Newfoundland, also under the direction of Dr. Henderson, gives supporting evidence.

The observations at all three Canadian stations give no indication of any effect of corpuscular eclipse. The Nova Scotian expedition of the U.S. Bureau of Standards had not reported at the time of writing.

The Northern Electric Company found no intensity change in 500 metre signals between Ottawa and Montreal, while the Canadian Marconi Company found no definite changes which could be ascribed to the eclipse in 22-37 metre transmissions across the Atlantic.

Observations at the Bureau of Standards, Washington, revealed effects on both Kennelly-Heaviside and Appleton regions. The methods adopted enabled a measurement to be made of the critical frequency just capable of penetrating each region at vertical incidence. Penetration of the lower region would be indicated by a sharp change in the retardation time of the radio echo, from that corresponding to the lower region to the much higher value corresponding to the upper region. Penetration of the upper (and more highly ionised) region would be indicated by the absence of an echo on the relatively high frequency which had first penetrated the lower region without measurable reflection, but had still, below the critical value, been reflected from the Appleton region. The Bureau of Standards reports that the conclusions to be drawn from the observed effects on the Appleton layer are still under consideration. For the Kennelly-Heaviside layer, however, the critical frequency of penetration was lower by about $1000 \mathrm{kc}$./sec. at the end of optical eclipse than before and after eclipse. The minimum critical frequency was reached about five minutes after the maximum of partial optical eclipse at Washington. This decrease of critical frequency indicates that the partial ultra-violet eclipse at Washington, with a duration of about an hour and a half, was accompanied by a very slightly lagging reduction of something between 35 and 60 per cent in the density of ionisation in the KennellyHeaviside region.

The provisional conclusions to be drawn from this assembly of data may now be summarised.

Optical Eclipse.-The evidence from the U.S. Bureau of Standards, National Research Council of Canada, and British Post Office establishes beyond any doubt the importance of ultra-violet light as a principal ionising agent for the KennellyHeaviside layer.

The evidence from Canada establishes a similar ultra-violet effect for the Appleton region, and the Bureau of Standards data probably support this evidence.

The evidence from European short-base echo stations was not expected to bear on the optical eclipse, nor does it do so.

Particle Eclipse.-No evidence is yet available from the only stations even moderately favourably situated for observations on the effects of the particle eclipse.

The Canadian and United States stations, unfavourably situated in place (and the Dutch station, unfavourably situated in place and time), show no effects at all suggestive of particle eclipse.

The British stations, unfavourably situated in time, give very slight suggestions of effects from the eclipse of particles of velocity somewhat below the 1000 miles per minute assumed in the computations of track and time.

In the light of all available evidence, weighted according to situation, the significance of ultraviolet light as a principal ionising agent for the ionosphere as a whole is established; the possible significance of neutral corpuscles is not established, but is not wholly excluded; it remains to be tested under more favourable conditions and in the light of our rapidly growing knowledge of the climatology of the ionosphere.

This discussion opened with a summary of the defects, in time and place, of the 1932 eclipse from the point of view of ionospheric observation. It may appropriately close with an indication of the merits of a 1933 eclipse. Chapman has shown that the student of the ionosphere is less interested in the distinction between total and nearly total eclipse than is the astronomer. The annular eclipse of Aug. 21,1933 , is of sufficient magnitude in respect of ionisation effects, and it has the overwhelming advantage that maximum eclipse for light and for particles alike can be observed in inhabited land areas at times when the diurnal curve of ionisation

No. 3280 , VoL. 130] 
density in the ionosphere is rising comparatively slowly or is near a stationary point: that is, the optical eclipse might be observed in the morning, but well after sunrise, the particle eclipse near noon. The low latitude of the eclipse track suggests another considerable advantage, the eclipse phenomena unrolling at such a low speed that the cumulative effects on ionisation may well outweigh the 7 per cent defect in magnitude of the eclipse. It would appear most desirable that an adequate organisation should be worked out for observations on the optical eclipse near Delhi, with corresponding observations on the particle eclipse.

The Superintendent of the Radio Research Station, Slough, would be grateful for information as to the station of origin of pulse signals on a frequency of $3.56 \mathrm{mc} . / \mathrm{sec}$. (pulses at 50 per sec.) which were accidentally observed at Slough during the control experiments for the eclipse. The pulse signals ceased at 2020 G.M.T. on Sept. 1 and at 2100 on Sept. 2. The echo pattern, showing marked magneto-ionic splitting, was recorded simultaneously with that from local pulses; the comparison of distance and direction data might yield useful results.

1 Appleton, Observatory, March 1932.

Appleton and Naismith, Proc. Rou. Soc., A, 137, 36 ; 1932.

Chapman, Mom. Not. Roy. Ast. Soc., 92, 413; 1932

Miller, Mon. Not. Roy. Ast. Soc., 92, $421 ; 1932$

Appleton and Chapman, NATURE, 129, 757, May 21, 1932

2 Appleton and Naismith, loc. cit

3 Schafer and Goodall, Proc. I.R.E., 20, 1131 ; 1932

4 Ranzi, Nature, 130, 368, Sept. 3, 1932.

\section{Current Constructive Theories in Psychology*}

\section{By Prof. Beatrice Edgell}

$\mathrm{O}^{\mathrm{N}}$ Aug. 29 there occurred the tercentenary of one who is often called 'the father of English psychology', John Locke, 1632-1704. His "Essay concerning Human Understanding " is primarily a theory of knowledge, not a system of psychology, but none the less there is much of psychological interest in the Essay, and it has had a profound influence on empirical psychology in the eighteenth and nineteenth centuries. We may regard it as a misfortune that what he described as a " historical plain method" should have been interpreted as a genetic study, and that his doctrine of simple and complex ideas should have been translated into a doctrine of psychological elements and compounds; but such has been the case. Historians trace a straight line of descent from the Essay of Locke to the "Analysis of the Phenomena of the Human Mind " by James Mill, and thus claim Locke as a founder of the Association school.

It may seem a far cry from 1632 to 1932 , but I want to consider some of the differing constructive theories of learning and knowledge offered by the psychologists of to-day in the light of the unreconciled methods and principles which find expression in the Essay.

We find first and foremost in the Essay a confusion of logical and psychological analysis; secondly, we find a theory that attributes the union of discrete ideas to their accidental association in time, introduced as an afterthought to the theory that ideas are united by the perception of their connexion or repugnancy.

To begin with the confusion of logical with psychological analysis. As Prof. Gibson has pointed out in his book " Locke's Theory of Knowledge ", at the time at which Locke was writing, the distinction between the elements of knowledge attainable by logical analysis and the simple beginnings of-knowledge attainable by genetic study was a distinction which it was wellnigh impossible for a writer to draw. Growth and development were conceptions which had a very different colour-

* From the presidential address to Section $\mathbf{J}$ (Psychology) of the British Association, delivered at York on Sept. 5 . ing from what they have for us to-day. They were, moreover, conceptions which had no literal application to knowledge. Knowledge for Locke was a structure the validity of which could be tested by taking it to pieces. Just as a logical analysis of the ultimate items into which, say, a building could be resolved and an inquiry into the material out of which it arose might lead one to much the same catalogue of stones and beams, so a logical analysis of knowledge into its elements seemed to have the same issue as an inquiry into the beginnings of knowledge. That which is simple in its content is easily confused with that which is simple in its origin. It is this confusion which lays Book II. of Locke's Essay open to much misunderstanding. Having in Book I. denied that mind is possessed of ideas at birth, and having claimed that all knowledge is founded upon, and derived from, experience, Locke seems by his account of the ' simple ideas' of sensation and reflection and of the 'complex ideas' built upon them to be offering a psychological constructive theory of knowledge.

There is much of great psychological value in this second book : Locke's frequent appeal to concrete illustrations, his references to children and animals, the famous citation of Molineux's problem whether a man whose sight was only restored to him in adult life would be able to distinguish by sight between a sphere and a cube. The book also contains his striking chapter on retention, vivid through its analogies but of paramount importance for psychology by reason of the statement added in the second edition: "This laying up of our ideas in the repository of the memory signifies no more but this, that the mind has a power in many cases to revive perceptions which it has once had, with this additional perception annexed to them, that it has had them before, and in this sense it is that our ideas are said to be in our memories, when indeed they are actually nowhere; but only there is an ability in the mind when it will to revive them again, and as it were paint them anew on itself, though some with more, some with less difficulty; some more lively, and others more

No. 3280, VoL. 130] 